\title{
Knowledge Management Solution for Achieving Sustainable Capacity of SMME
}

\author{
Ivars Majors* \\ Business and Management Department, LLU
}

\begin{abstract}
Due to the development of knowledge society, there is increased demand for using knowledge management $(\mathrm{KM})$ in an entrepreneurship as well as using information and communication technology (ICT). To achieve sustainable capacity it is necessary to promote KM and ICT in small, medium and microenterprises (SMME). KM is implemented successfully in the firms with large amount of employees. There are limited abilities to handle it for SMME. It is necessary to develop the model for implementation of KM for achieving sustainable capacity in SMME. The aim of this paper is to illustrate the model for strengthening sustainable capacity of SMME in transition to knowledge economy. Study of the bibliography was applied to define main dimensions of sustainable capacity of an enterprise. The active knowledge modelling method was applied to develop the model of KM solution for achieving sustainable capacity of SMME. As a result of research, a method for evaluation of sustainable development of SMME was developed. It reflects key elements for KM solution in SMME and consists of four interrelated sub-models such as goal model, business process model, concepts model, and information systems model. The model was evaluated in the target group as well as in the group of experts.
\end{abstract}

Key words: Knowledge management, sustainable capacity of an enterprise, enterprise knowledge development.

\section{Introduction}

Success of an enterprise is more and more dependent on its capability to create an effective environment for knowledge creation and application in order to provide value innovation rather than traditional factors of production (Maier, 2010). Knowledge management is an effective approach for enterprises in transformation to knowledgeintensive and knowledge-aware organizations in the knowledge economy as well as it demands that organizations integrate their activities, processes and systems to exploit their resources more efficiently and subsequently gain economies of scale and access to and from new market. The knowledge economy as phenomena is defined as production and services based on knowledge-intensive activities that contribute to an accelerated pace of technological and scientific advancement as well as equally rapid obsolescence (Powell \& Snellman, 2004). The demand of knowledge management solutions for small, medium and micro-enterprises (SMME) is raised by turbulently changing business environment. Knowledge management (KM) and effective use of information and communication technologies (ICT) are innovative instruments for SMME to become and remain competitive. ICT is a strategic resource that enables automation, monitoring, analysis and co-ordination to support the transformation of business processes (Barrios \& Nurcan, 2004) as well as supports knowledge management (Maier, 2010). This paper provides a conceptual model for achieving sustainable capacity in SMME by using knowledge management and ICT supported solution. The paper demonstrates the $\mathrm{KM}$ method that incorporates enterprise knowledge development (EKD) to identify needs of an enterprise and match them to an appropriate KM solution.

The aim of this paper is to illustrate the model of an innovative approach for strengthening sustainable capacity of SMME in transition to knowledge economy. The developed model is reflected and explained in the next section. Study of bibliography is applied to define main principles, dimensions and parameters of sustainable capacity of an enterprise. The active knowledge modelling approach is applied to develop the model of KM solution for achieving sustainable capacity of SMME. 
As a result of research, a method for evaluation of sustainable development of SMME was developed. The model reflects the key elements for KM solution in SMME and consists of four interrelated sub-models such as goal model, business process model, concepts model, and information systems model. This model was evaluated in the target group as well as in the group of experts.

The present article (1) reflects the result of reviews in scientific literature on achieving sustainable capacity of SMME, (2) discusses the main dimensions of sustainable capacity as well as factors for evaluation, and (3) reflects the model for achieving sustainable capacity of SMME. The paper is organized as follows: in section 1, research work from the literature is discussed related to the term of sustainable capacity, as well as dimensions are presented; section 2 discusses the KM aspects for sustainable development of SMME as well as appropriate methodology for development of the model; in section 3, the proposed model and the results of the evaluation are reflected; and the final section presents the conclusions.

\section{Materials and Methods}

Study of the bibliography was applied to define main dimensions of sustainable capacity of an enterprise. The active knowledge modelling method was applied to develop the model of KM solution for achieving sustainable capacity of SMME. Expert interview was applied to evaluate the modelling results.

\section{Results and Discussion Sustainable capacity of an enterprise}

The human economy is a subsystem of a finite global ecosystem which does not grow, even though it does develop. The growth of the economy cannot be sustained for a long period of time but it can be developed into greater potential (Delmar \& Wenneberg, 2010). Knowledge management and information technologies are effective instruments for SMME to become and remain competitive in today's rapidly changing and hyper-competitive business environment (Majors, 2010).

Sustainable development from an enterprise perspective means rethinking how business is being performed (Wong, 2010). It is applied in the strategies and activities that meet the needs not only of an enterprise and stakeholders but also of the society and environment. It serves for (1) changing the business organization's competitive landscape, (2) influencing the way in which the organizations develop their resources, capabilities, and activities, (3) influencing the strategic nature of the organization, and (4) promoting the organization's reputation and innovation as persistent source of competitive advantage (Wong, 2010).

General definition of sustainability of natural ecosystems can be defined as the dynamic equilibrium between natural inputs and outputs, modified by external events such as climate change and natural disasters (Epstein, 2008). Sustainability of the systems point of view is the capacity of a system to maintain output at a level approximately equal to or greater than its historical average, with the approximation determined by the historical level of variability. Sustainable development is development that meets the need of current generation without compromising the ability of future generations to meet their needs and aspirations. It has to improve the quality of human life while living within the carrying capacity of supporting ecosystem (Bell \& Morse, 2010).

For enterprises, a sustainability framework or model of social, environmental and economic performance creates a powerful opportunity to create enduring value for not only stakeholders but as well as for employers end society. The corporate sustainability model describes the input, processes, outputs, and outcomes necessary to implement a successful sustainability strategy (Epstein, 2008).

Sustainable capacity of an enterprise has to be viewed from the perspective of the system theory because of its nature. From organizational theory, an enterprise is a system that acts in its environment. According to the systems theory definition, a system is a set of two or more elements that satisfies the following three conditions (Skyttner, 2005):

- the behaviour of each element has an effect on the behaviour of the whole;

- the behaviour of the elements and their effects on the whole are independent;

- subgroups of the elements are formed, all have an effect on the behaviour of the whole, but none has independent effect on it.

A SMME is an open system which is dependent on its environment because of exchange of content, energy, information and knowledge (Skyttner, 2005). According to this it is necessary to take into account all aspects of an enterprise by defining the term sustainable capacity. The author of the present paper has defined the following six dimensions 


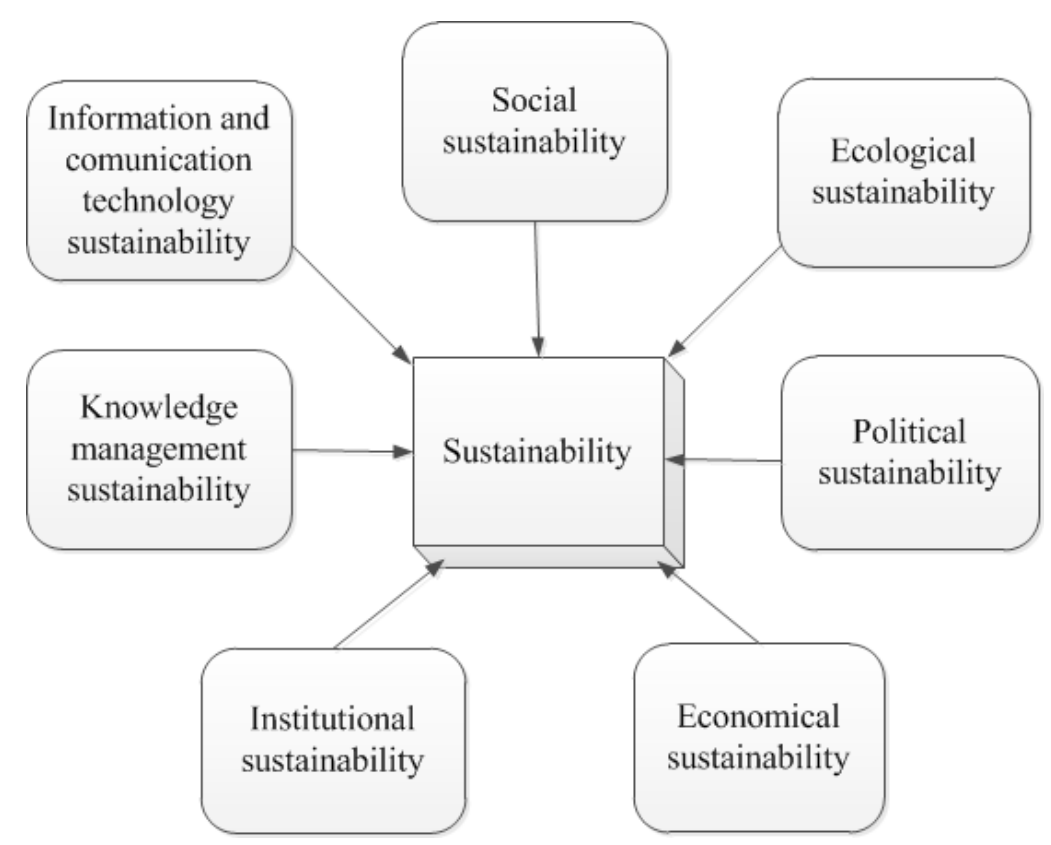

Fig. 1. Dimensions of the sustainability of an enterprise.

of sustainability from the study of the scientific literature (Assefa \& Frostell, 2007; Choi \& Sirakaya, 2006; Singh, Murty, \& Dikshit, 2009; Bikse, 2007; Davenport \& Prusak, 2000; Tiwana, 2002; Handzic, 2004; Cooper, 2006; Ein-Dor, Myers, \& Raman, 2006; Maier, 2010) (Fig. 1):

- social sustainability including organizational culture;

- ecological and environmental sustainability including appropriate use of natural resources;

- political sustainability including support from governmental institutions and rural municipality;

- economical sustainability including efficiency in the long-time scale;

- institutional sustainability including effective business processes management;

- knowledge management sustainability including supporting knowledge-intensive business processes;

- information and communication technology sustainability including application of $\mathrm{KM}$ solutions.

\section{Enterprise knowledge development for KM implementation in SMME}

Active knowledge modelling enables the common understanding of all the pertinent aspects, and the clear description of problems in a particular subject area (Lillehagen \& Krogstie, 2008). Application of a particular approach provides a powerful tool for development of knowledge management solution by the definition of various design alternatives as well as a mechanism to analyse these options for design implementation at the strategic, tactical, operational, and technological levels (Whitman \& Huff, 2001).

The following methodologies were chosen for benchmarking (Table 1):

- Yu methodology - strategic relationship development (Horkoff \& Yu, 2009);

- EKD (Enterprise Knowledge Development) - enterprise modelling method (Bubenko \& Kirikova, 1999; Persson, 2001);

- BPR (Business Process Redesign) - method oriented to business process redesign and optimization (Gao \& Krogstie, 2009);

- Business Process Management Systems method for business process analysis from organizational, functional, and behaviour point of view (Carvalo \& French, 2009);

- DRM (Decision Relationship Model) - reflecting actors, processes, input flows und decisions (Shahzad \& Zdravkovic, 2009);

- Service-Driven Information Systems Evaluation - provides analysis of business processes and abilities to use resources accessible to enterprises (Arni-Bloch, Ralyte, \& Leonard, 2009);

- Zachman Enterprise Architecture is a twodimensional classification scheme for descriptive representation of an enterprise which consists of different characteristics of the final product 
Table 1

Benchmarking of the methods used for development of knowledge management solution

\begin{tabular}{|c|c|c|c|c|c|c|c|}
\hline $\begin{array}{l}\text { Defining } \\
\text { processes } \\
\text { compared } \\
\text { with goals and } \\
\text { resources }\end{array}$ & $-/+$ & + & $+/-$ & $+/-$ & + & + & $+/-$ \\
\hline $\begin{array}{l}\text { Defining } \\
\text { hierarchical } \\
\text { structure }\end{array}$ & - & + & + & + & - & - & + \\
\hline $\begin{array}{l}\text { Defining } \\
\text { requirements } \\
\text { for ICT support }\end{array}$ & - & + & - & + & + & $+/-$ & $+/-$ \\
\hline
\end{tabular}

Source: based on Majors, 2009.

(continuing education framework) (Zachman, 2006)

The enterprise knowledge development (EKD) methodology is chosen as the enterprise modelling method. The EKD was developed some years ago and is used by business consultancy companies with increasing frequency. This method has been the subject of research in a number of multinational European projects, including 5th framework programme. It has proved its effectiveness both in the business and public sector by providing a framework for stating, modelling, and reasoning regarding pertinent knowledge in difficult problem situations which typically occurs in organisations and society. The EKD aims at setting an organisation's vision, mission and goals, providing guidance in restructuring and changing different processes (Bubenko \& Kirikova, 1999).

\section{The model of KM solution for sustainable development of SMME}

The active knowledge modelling approach was applied for the development of a KM model in SMME. The developed model is presented in
Figure 2. The Enterprise Knowledge Development (EKD) method is used as a modelling method. The method includes development of six interrelated submodels: goal, business processes, business rules, actors, concepts, and information system's requirements. The goal model reflects the main goal and objectives which have to be achieved in a particular case. The business process model reflects processes and the data flow between them. The business rule model reflects rules which have to be taken into consideration to achieve the main goal in a business process. The actors model reflects the main actors participating in business processes and being responsible for achieving the goals. The concepts model describes the main concepts used in other models. The information system's requirements model reflects the concept of appropriate software and hardware for supporting the business processes and achieving the goals.

For a particular case, four submodels were developed. Figure 2 reflects the model consisting of the goals model, business process model, concepts model, as well as information and communication model. The goal model consists of two parts: strategic 


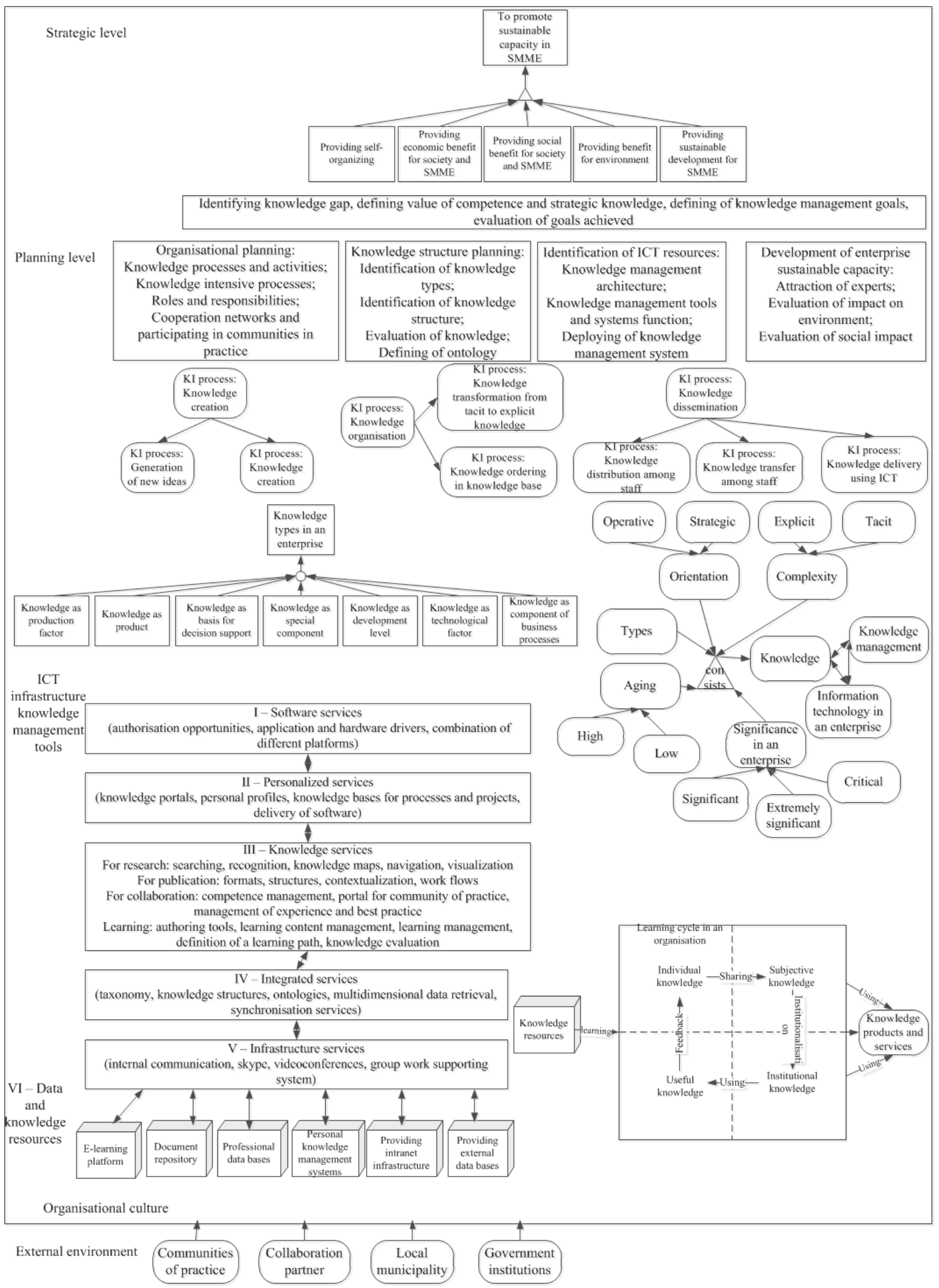

Source: based on Maier, 2010.

Fig. 2. The EKD model for KM implementation in SMME. 
level, and planning level. Main goals and subgoals are reflected in the strategic level.

Strategic level (goal model) shows the main goal of $\mathrm{KM}$ implementation as well as subgoals to be fulfilled in SMME (Fig. 2). To promote sustainable capacity in SMME, self-organizing should be provided. The SMME has to ensure economic and social benefits for society. To implement the defined goals, the following actions can be pointed out according to the literature:

- providing benefit for environment including calculation of ecological footprint;

- identification of knowledge gap which reflects the gap between knowledge flow appropriate for knowledge-intensive processes and actual knowledge in SMME;

- defining of knowledge management goals and evaluation of goals achieved.

Planning level (process model) shows the main processes to be implemented for successful KM in the SMME (Fig. 2). This level shows also concepts related to the subject of knowledge and its management. The processes are divided into four subcategories:

- organizational planning, which includes knowledge processes and activities, knowledgeintensive processes, role and responsibilities of actors, cooperation networks, and participation in communities of practice;

- knowledge structure planning, which includes identification of knowledge type, identification of knowledge structure, knowledge evaluation, and definition of an ontology;

- identification of ICT resources, which includes knowledge management architecture, analysis of KM tools and system's function, as well as deploying of knowledge management system;

- development of sustainable capacity in an enterprise, which includes attraction of experts, evaluation of the impact on environment as well as social impact.

Business process model includes also knowledgeintensive (KI) business processes which are separated into three types:

- knowledge creation, which includes generation of new ideas;

- knowledge organization, which includes transformation of tacit knowledge into explicit form and ordering them into a knowledge base;

- knowledge dissemination, which includes distribution, transfer among the staff, and delivery through ICT.
Concepts model explains two main concepts: knowledge, and types. Knowledge itself can be categorized in different types, orientation, as well as complexity. Important is to identify different types of knowledge. Figure 2 reflects the types of knowledge which an organization could use during its business processes. Knowledge could be:

- as production factor for a product or a service;

- as product which is delivered for customers;

- basis for support of decisions to be taken during business processes;

- special component for knowledge-intensive processes;

- resource for development;

- as technological factor for development of a new product or services;

- component in the knowledge-intensive business processes.

The information and communication technology infrastructure and $\mathrm{KM}$ tools model shows data and knowledge resources as well as different services (Fig. 2). Elements identified in this model are divided into three parts:

- technology part (including platforms for KM implementation);

- service part (including software, personalized, knowledge, infrastructure, and integrated services);

- development of knowledge products and services (including knowledge resources and types as well as learning cycle in an organization).

Figure 2 reflects the model for implementation of the knowledge management's solution for sustainable development of a SMME.

\section{Conclusions}

1. Ecological, political economical, institutional, knowledge management, information and communication technology sustainability dimensions include all aspects of the term sustainable capacity.

2. The use of the active modelling method in the development of knowledge management solution provides a wide range of options to implement a more dynamic and sophisticated knowledge development.

3. IT technologies and services provide opportunity to identify the knowledge management process and the needs for an organization as well as services necessary for development of knowledgeintensive processes. Such an approach promotes provision of an individualized new knowledge 
development because it offers possibility of linking the processes within the enterprise.

4. The results of an unstructured interview in the group of experts show the necessity of a particular KM solution for sustainable development of SMME.

\section{References}

1. Arni-Bloch, N., Ralyte, J., \& Leonard, M. (2009). Service-driven information systems evaluation: Handling integrity constraints consistency. In The Practice of Enterprise Modeling: Proceedings of Second IFIP 8.1. Working conference, PoEM (pp. 191-206). Germany: Springer.

2. Assefa, G., \& Frostell, B. (2007). Social sustainability and social acceptance in technology assessment: A case study of energy technologies. Technology in Society, 29(1), 63-78.

3. Barrios, J., \& Nurcan, S. (2004). Model driven architectures for enterprise information system. In 16th International Conference "Advanced Information Systems Engineering”, CAiSE, 2004 (pp. 3-19). Germany: Springer.

4. Bell, S., \& Morse, S. (2010). Sustainability indicators. Measuring the immeasurable? UK: Earthscan.

5. Bikse, V. (2007). Ekonomikas teorijas pamatprincipi. Rīga: SIA „Izglītības soḷi”.

6. Bubenko, J.A., \& Kirikova, M. (1999). Improving the quality of requirements specifications by enterprise modelling. In A.G. Nilsson, Ch. Tolis \& Ch. Nellborn (Eds.), Perspectives on business modelling: Understanding and changing organisations (pp. 243-266). Berlin: Springer.

7. Carvalo, J.P., \& French, X. (2009). In the use of $i^{*}$ for architecting hybrid systems: A method and an evaluation report. In The Practice of Enterprise Modeling: Proceedings of Second IFIP 8.1. Working conference, PoEM 2009 (pp. 38-53). Germany: Springer.

8. Choi,H.Ch., \& Sirakaya, E. (2006). Sustainability indicators for managing community tourism. Tourism Management, 27, 1274-1289.

9. Cooper, P.L. (2006). An evolutionary model for KMS success. In Proceedings of the 39th Hawail International Conference on System Sciences (pp. 1-10). Hawaii: IEEE.

10. Davenport, T.H., \& Prusak, L. (2000). Working knowledge. How organizations manage what they know.? USA: Harvard Business School Press.

11. Delmar, F., \& Wenneberg, K. (2010). Knowledge Intensive Entrepreneurship. The Birth, Growth and Demise of Entrepreneurial Firms. USA: Edward Elgar Publishing, Inc.

12. Ein-Dor, P., Myers, M., \& Raman, K.S. (2006). IT industry development and the knowledge economy: A four contry study. Advanced Topics in Global Information Management, 5, 23-49.

13. Epstein, M.J. (2008). Making sustainability work. Best practices in managing and measuring corporate social, environmental, and economic impact. USA: Greenleaf Publishing Ltd.

14. Gao, Sh., \& Krogstie, J. (2009). A combined framework for development of business process support system. In The Practice of Enterprise Modeling: Proceedings of Second IFIP 8.1. Working conference, PoEM (pp. 115-129). Germany: Springer.

15. Handzic, M. (2004). Knowledge management through the technology glass. Singapore: World Scientific Publishing.

16. Horkoff, J., \& Yu, E. (2009) Evaluating goal achievement in enterprise modeling - An interactive procedure and experiences. In The Practice of Enterprise Modeling: Proceedings of Second IFIP 8.1. Working conference, PoEM (pp. 145-160). Germany: Springer.

17. Lillehagen, F., \& Krogstie, J. (2008). Active knowledge modelling of enterprises. Germany: Springer-Verlag Berlin Heidelberg.

18. Maier, R. (2010). Knowledge management systems. Information and communication technologies for knowledge management (3rd ed.). Germany: Springer-Verlag Berlin Heidelberg.

19. Majors, I. (2009). Application of the enterprise modelling for the knowledge management solution in achieving sustainable capacity of SME. In Annual Proceedings of Vidzeme University of Applied Sciences "ICTE in Regional Development”, 2009/2010, 42-51.

20. Majors, I. (2010). ICT and knowledge management models for promotion of SME's competitiveness. The International Journal of Technology, Knowledge and Society, 6, 7-20.

21. Persson, A. (2001). Enterprise modelling in practice: Situational factors and their influence on adopting a participative approach. Ph.D. thesis, Sweden, Department of Computer Science. 
22. Powell, W.W., \& Snellman, K. (2004). The knowledge economy. Annu. Rev. Sociol., 30, 199-220.

23. Shahzad, K., \& Zdravkovic, J. (2009). A goal-oriented approach for business process improvement using process warehouse data. In The Practice of Enterprise Modeling: Proceedings of Second IFIP 8.1. Working conference, PoEM (pp. 84-98). Germany: Springer.

24. Singh, R.K., Murty, H.R., \& Dikshit, A.K. (2009). An overview of sustainability assessment methodologies. Ecological Indicators, 9(2), 189-212.

25. Skyttner, L. (2005). General systems theory. Problems. Perspectives. Practice. Singapore: World Scientific Publishing Ltd.
26. Tiwana, A. (2002). The knowledge management toolkit: Orchestrating IT, strategy, and knowledge platforms (2nd ed.). USA: Prentice Hall PTR.

27. Whitman, L., \& Huff, B. (2001). On the use of enterprise models. The International Journal of Flexible Manufacturing Systems, 13, 195-208.

28. Wong, D.M.L. (2012). Knowledge management catalyst for sustainable development. 2010 International Symposium in Information Technology, ITSim, 3, 1444-1449.

29. Zachman, J.A. (2006). The Zachman framework for enterprise architecture: Primer for enterprise engineering and manufacturing [e-book in PDF format]. Published by Zachman Framework Associates Metadata Systems Software Inc. 